University of Nebraska - Lincoln

DigitalCommons@University of Nebraska - Lincoln

December 2007

\title{
Reduced intestinal colonization of adult beef cattle by Escherichia coli 0157:H7 tir deletion and nalidixic-acid-resistant mutants lacking flagellar expression
}

\author{
Gustavo Bretschneider \\ University of Nebraska - Lincoln \\ Emil M. Berberov \\ University of Nebraska - Lincoln \\ Rodney A. Moxley \\ University of Nebraska - Lincoln, rmoxley1@unl.edu
}

Follow this and additional works at: https://digitalcommons.unl.edu/vetscipapers

Part of the Veterinary Medicine Commons

Bretschneider, Gustavo; Berberov, Emil M.; and Moxley, Rodney A., "Reduced intestinal colonization of adult beef cattle by Escherichia coli 0157:H7 tir deletion and nalidixic-acid-resistant mutants lacking flagellar expression" (2007). Papers in Veterinary and Biomedical Science. 82.

https://digitalcommons.unl.edu/vetscipapers/82

This Article is brought to you for free and open access by the Veterinary and Biomedical Sciences, Department of at DigitalCommons@University of Nebraska - Lincoln. It has been accepted for inclusion in Papers in Veterinary and Biomedical Science by an authorized administrator of DigitalCommons@University of Nebraska - Lincoln. 
Published in Veterinary Microbiology 125:3-4 (December 15, 2007), pp. 381-386; doi:10.1016/j.vetmic.2007.06.009

Copyright (C) 2007 Elsevier B.V. Used by permission. http://www.sciencedirect.com/science/journal/03781135

Submitted March 8, 2007; revised June 11, 2007; accepted June 14, 2007; published online June 19, 2007.

Short COMMUNiCATION

\title{
Reduced intestinal colonization of adult beef cattle by Escherichia coli $\mathrm{O} 157: \mathrm{H} 7$ tir deletion and nalidixic-acid-resistant mutants lacking flagellar expression
}

\author{
Gustavo Bretschneider a, Emil M. Berberov ${ }^{1, a}$, and Rodney A. Moxley ${ }^{\mathrm{a}, *}$ \\ ${ }^{a}$ Department of Veterinary and Biomedical Sciences, University of Nebraska-Lincoln, \\ Fair St. and East Campus Loop, Lincoln, NE 68583-0905, USA \\ * Corresponding author: 111 Veterinary Basic Sciences, University of Nebraska-Lincoln, \\ Lincoln, NE 68583-0905, USA. Tel.: 402 472-8460; fax: 402 472-9690; email: rmoxley1@unl.edu \\ ${ }^{1}$ Present address: Vaccine and Infectious Disease Organization, University of Saskatchewan, \\ 120 Veterinary Road, Saskatoon, SK S7N 5E3, Canada
}

\begin{abstract}
The importance of the Escherichia coli O157:H7 translocated intimin receptor (Tir) protein in intestinal colonization and the effect of infection with $\operatorname{Tir}^{+}$strains on protection against subsequent challenge was studied in adult beef cattle. Cattle were orally inoculated (C1) with a Shiga toxin- $2^{+}$E. coli O157:H7 strain that was Tir ${ }^{+}$ or $\mathrm{Tir}^{-}$, and 42 days later were re-challenged $(\mathrm{C} 2)$ with the nalidixic acid $(\mathrm{Nal})^{\mathrm{R}}$ parent strain to test whether prior infection had any effect on fecal shedding. During the first 14 days post-C1, the $\mathrm{Nal}^{\mathrm{S}}$ wildtype (WT) strain was shed at significantly higher levels and for a longer period than the other strains; however, the mean levels of shedding of the $\mathrm{Nal}^{\mathrm{R}}$ and $\Delta$ tir complemented strains were not significantly different from that of the $\operatorname{Tir}^{-}$strains. The $\Delta t i r$, Tir complemented mutant, and $\Delta t i r$ vector control strains inadvertently did not express flagellin, and did not effectively colonize the intestine. We were unable to determine whether Tir exposure at $\mathrm{C} 1$ had any effect on protection. Further, those given an initial inoculation with a non-flagellated variant of $E$. coli $\mathrm{O} 157: \mathrm{H} 7$ were more susceptible to a second challenge with motile E. coli $\mathrm{O} 157: \mathrm{H} 7$ than those originally inoculated with motile strains. The cause of the loss of expression of flagellin was not addressed. We suggest that either the flagellum or a factor that regulates both its production and that of some other effector has a significant function in colonization.
\end{abstract}

Keywords: Escherichia coli O157:H7, cattle, colonization, translocated intimin receptor, flagella

\section{Introduction}

Escherichia coli $\mathrm{O} 157: \mathrm{H} 7$ is an important food-borne pathogen that causes hemorrhagic colitis and hemolytic uremic syndrome in humans (Griffin et al., 1988). Cat- tle are an important reservoir host of E. coli $\mathrm{O} 157: \mathrm{H} 7$, in which the organism colonizes the intestinal tract and is shed in the feces (Cray and Moon, 1995). The mucosa of the terminal rectum is a principal site of colonization (Naylor et al., 2003). Colonization of this site involves 
the formation of attaching-effacing (A/E) lesions (Naylor et al., 2005). The bacterial outer membrane protein intimin and proteins secreted via the type III secretion system (TTSS), viz., the translocated-intimin receptor (Tir) and several E. coli-secreted proteins (Esps), have significant functions in $\mathrm{A} / \mathrm{E}$ lesion induction (Hartland et al., 2000).

Cattle are susceptible to re-infection under natural conditions (Khaitsa et al., 2003). However, experimentally, young calves shed fewer organisms upon re-exposure to the homologous strain (Naylor et al., 2007). The objectives of this study were to determine whether inactivation of tir reduces the magnitude and duration of E. coli $\mathrm{O} 157: \mathrm{H} 7$ fecal shedding in adult cattle, and to compare the effects of initial infection with $\mathrm{Tir}^{+}$and $\mathrm{Tir}^{-}$ strains on shedding following a second challenge.

\section{Materials and methods}

\subsection{Experimental animals}

Thirty adult beef cattle (mean age, $\sim 16$ months) that tested negative for E. coli O157:H7, Salmonella spp., coccidia and nematodes in the feces, and negative for bovine viral diarrhea virus in the serum were included in the study. Cattle were individually housed in biosafety level (BL)-2 containment rooms that had individual floor drains. The floors and walls of each room were thoroughly washed once daily.

\subsection{Inoculum strains and culture methods}

Strains used in this study were cultured in LB with appropriate antibiotic selection (Table 1). Cultures were incubated overnight at $37^{\circ} \mathrm{C}$ with shaking, unless otherwise stated. For motility tests, LB broth cultures were incubated overnight on blood agar, then stabbed and incubated at $37^{\circ} \mathrm{C}$ overnight in tube motility medium or $12 \mathrm{~h}$ in tryptone agar plates.

\subsection{Western blots and electron microscopy}

Each strain was tested for Tir expression by Western blot as previously described (DeVinney et al., 1999) with minor modifications. Whole-bacterial extracts were used to test for $\mathrm{H} 7$ flagellin expression (Girón et al., 2002). Nitrocellulose membranes were incubated with a 1:1000 dilution of a commercial rabbit anti-H7 antiserum (Difco), followed by a 1:2000 dilution of goat antirabbit IgG conjugated to horseradish peroxidase (Gibco $\left.\mathrm{BRL}^{\circledR}\right)$. LB cultures, processed by routine methods for transmission electron microscopy (TEM) were examined for flagella.

\subsection{Experimental design}

Six cattle each were inoculated with a $\mathrm{Tir}^{+}$or $\mathrm{Tir}^{-} E$. coli $\mathrm{O} 157: \mathrm{H} 7$ strain (Table 1) and re-challenged 42 days later $(\mathrm{C} 2)$ with the $\mathrm{Tir}^{+} \mathrm{Nal}^{\mathrm{R}}$ parent strain. In all cases,

Table 1. E. coli O157:H7 strains used in this study

\begin{tabular}{|c|c|c|c|c|c|c|}
\hline \multirow[t]{2}{*}{ Strains } & \multicolumn{4}{|c|}{ Characteristics } & \multirow[t]{2}{*}{ Comments } & \multirow[t]{2}{*}{ Reference and/or source } \\
\hline & Tir $^{\mathbf{a}}$ & $\mathrm{Nal}^{\mathrm{b}}$ & $\mathrm{Cm}^{\mathrm{c}}$ & Tet $^{d}$ & & \\
\hline Wild-Type 86-24 & + & S & S & S & & Griffin et al. (1988) \\
\hline $86-24 \mathrm{Nal}^{\mathrm{R}}$ & + & $\mathrm{R}$ & $\mathrm{S}$ & $\mathrm{S}$ & Spontaneous $\mathrm{Nal}^{\mathrm{R}}$ mutant & DeVinney et al. (1999) \\
\hline $86-24 \Delta t i r$ & - & $\mathrm{R}$ & $\mathrm{S}$ & $\mathrm{S}$ & Non-polar tir deletion & DeVinney et al. (1999) \\
\hline $86-24 \Delta t i r(\mathrm{pEH} 86)^{\mathrm{e}}$ & + & $\mathrm{R}$ & $\mathrm{R}$ & $\mathrm{S}$ & tir gene cloned into $\mathrm{pACYC} 184$ & DeVinney et al. (2001) \\
\hline 86-24 $\Delta t i r(\mathrm{pACYC} 184)$ & - & $\mathrm{R}$ & $\mathrm{R}$ & $\mathrm{R}$ & 86-24 $\Delta$ tir transformed with pACYC184 & This study \\
\hline
\end{tabular}

${ }^{\text {a }}$ Presence $(+)$ or absence $(-)$ of tir gene.

${ }^{\mathrm{b}}$ Nalidixic acid (Nal).

c Chloramphenicol (Cm).

$\mathrm{d}$ Tetracycline (Tet). Sensitivity ( $\mathrm{S}=$ sensitive and $\mathrm{R}=$ resistant).

${ }^{\mathrm{e}} \mathrm{pEH} 86$ is pACYC184 with tir cloned into BamHI-SalI sites. tir is under the control of the tetracycline resistance gene promoter. 
the inoculum dose was $1 \times 10^{9} \mathrm{CFU}$ given in the feed, and cattle were observed to consume the entire feed sample. Fecal samples were collected daily from the centers of fresh pats on the floor for 14 days after $\mathrm{C} 1$ and $\mathrm{C} 2$, and on alternate days from days 14 to 42 after $\mathrm{C} 1$.

\subsection{Fecal cultures and identification of isolates}

Each fecal sample was cultured by direct plating (DP) for quantification of shedding levels (CFU/g), and GN broth enrichment with antibiotics followed by $0157 \mathrm{im}-$ munomagnetic separation (E-IMS) and plating to detect levels below that detectable by DP. E-IMS was done as described (Smith et al., 2005), with the exception of Nal and chloramphenicol $(\mathrm{Cm})$ selection at the plating step where appropriate. For DP, $1 \mathrm{~g}$ of feces was added to $9 \mathrm{~mL}$ buffered peptone water and serial 10 -fold diluted to $10^{-5}$. One hundred microliter of each dilution was spread onto each of two sorbitol MacConkey (SMAC) plates containing cefixime $(0.5 \mu \mathrm{g} / \mathrm{ml})$ and potassium tellurite $(2.5 \mu \mathrm{g} / \mathrm{ml})$ to quantify WT, or $40 \mu \mathrm{g} / \mathrm{ml} \mathrm{Nal}$ to quantify all other strains. Plates were incubated 18 $24 \mathrm{~h}$ at $37^{\circ} \mathrm{C}$. One to three isolates on each E-IMS or DP count plate were confirmed to be E. coli $\mathrm{O} 157: \mathrm{H} 7$ by standard testing (Smith et al., 2005). Non-sorbitol-fermenting isolates on SMAC-Nal plates from cattle inoculated with $\Delta t i r$ (pEH86) or $\Delta$ tir (pACYC184) were tested for the chloramphenicol acetyltransferase (cat) gene by colony hybridization and subculture onto SMAC-Cm $(40 \mu \mathrm{g} / \mathrm{ml})$ agar. Hybridizations used a horseradish peroxidase-labeled EcoRI-XbaI (1425-bp) fragment of pACYC184, and a chemiluminescence system (ECL, Amersham Pharmacia).

\subsection{Statistical analysis}

The mean magnitude and duration of fecal shedding was estimated for the first 14 days post- $\mathrm{C} 1$ and post-C2. The magnitude of shedding was determined as the geometric mean expressed as $\log _{10} \mathrm{CFU} / \mathrm{g}$ (wet weight) of feces. The duration of shedding based on DP or E-IMS, expressed as the percentage of days in which E. coli O157:H7 was detected was determined. Magnitude and duration of fecal shedding, when the latter was assessed either by DP or E-IMS, was assessed by Spearman's correlation analysis (Proc CORR, SAS, 1999). Data were analyzed as described by La Ragione et al. (2005).

\section{Results}

\subsection{Phenotypic characterization of the inoculum strains}

The in vitro growth rates of the different strains were not significantly different $(P>0.05)$. The predicted $\mathrm{Tir}^{+}$ and $\operatorname{Tir}^{-}$status of each strain (Table 1) was confirmed by Western blot (data not shown). The $\mathrm{Nal}^{\mathrm{R}} \Delta$ tir and derivative strains were non-flagellated, lacking evidence of flagellin by Western blot (Figure 1) and flagella by TEM (data not shown). Moreover, the $\mathrm{Nal}^{\mathrm{R}}$ parent strain produced less flagellin (Figure 1) and was less motile than the wild-type (WT; Nal-sensitive) strain (data not shown).

\subsection{Magnitude and duration of E. coli O157:H7 shed- ding in feces}

A highly significant correlation was detected between the magnitude and duration of fecal shedding when the latter was assessed either by DP $(r=0.99, P<0.0001$, $\left.r^{2}=98 \%, n=30\right)$ or E-IMS $(r=0.92, P<0.0001$, $r^{2}=85 \%, n=30$ ). During the first 14 days post-C1, the WT strain was shed at significantly higher levels and for a longer period $(P<0.05)$ than the other strains, as determined both by DP and E-IMS (Figure 2). The mean levels of shedding of the $\mathrm{Nal}^{\mathrm{R}}$ parent and $\Delta$ tir (pEH86) groups were not significantly different from that of the Tir $^{-}$groups $(P>0.05)$. However, 1-2 animals in each of these $\mathrm{Tir}^{+}$groups shed at levels comparable to WT, in contrast to no animals shedding at these levels in the Tir groups (Figure 2). Between days 14 and 42 post-C1, the levels of shedding among the five treatment groups were not significantly different ( $P=0.5$; data not shown). Isolates quantified as $\Delta$ tir (pEH86) or $\Delta$ tir (pACYC184) were confirmed to have retained their plasmids. Based on the E-IMS procedure, the percent of positive days of detection of fecal shedding, as a measure of duration

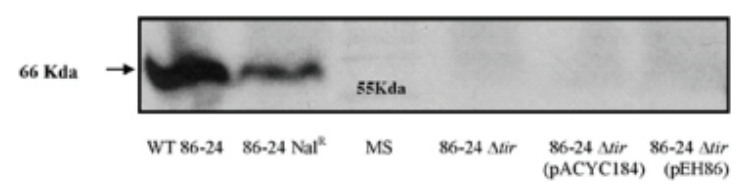

Figure 1. Expression of flagellin by E. coli O157:H7 strains. Mass standards (MS) are shown. Molecular weight of $\mathrm{H} 7$ flagellin is $66 \mathrm{kDa}$. 


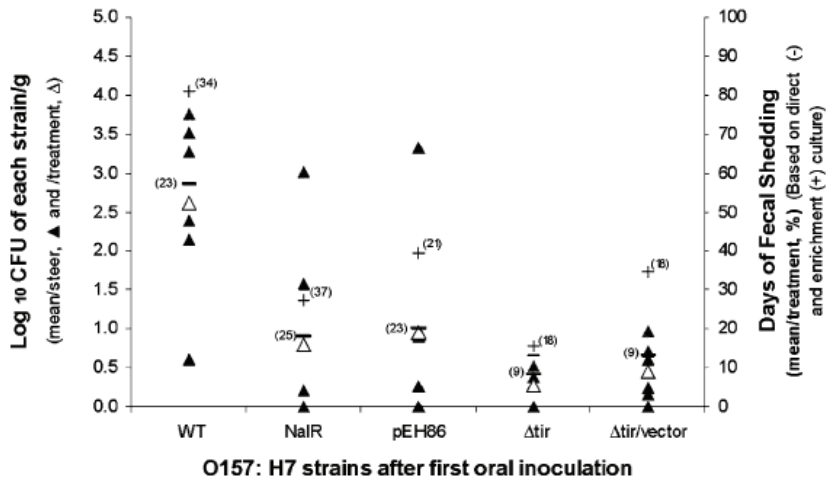

Figure 2. Magnitude (mean per steer, $\mathbf{\Delta}$; mean per treatment, $\Delta$; $\log _{10} \mathrm{CFU} / \mathrm{g}$ ) and duration of fecal shedding (mean per treatment; percentage of days positive), as detected by direct plating (DP) and enrichment (E-IMS) culture. Cattle $(n=6 ; \boldsymbol{\Delta}$ may be overlapped in 0 value) were orally inoculated with $\mathrm{Tir}^{+}$or $\mathrm{Tir}^{-}$E. coli $\mathrm{O} 157: \mathrm{H} 7$ strains. Cattle were individually housed and inoculated in isolation rooms and fecal shedding was monitored daily for 14 days. Standard deviations for the duration of fecal shedding based on DP and E-IMS culture are shown in parentheses.

after 14 days post-C1, was $33.0 \%$ for WT; $12.0 \%$ for $\mathrm{Nal}^{\mathrm{R}} ; 2.4 \%$ for $\Delta$ tir; $11 \%$ for $\Delta$ tir (pEH86); and $3.6 \%$ for $\Delta$ tir (pACYC184). Although these numerical means followed a pattern consistent with the hypothesis that Tir enhances colonization, the results were not significant $(P=0.2)$.

To assess whether previous exposure to Tir protein via enteric infection induces any protection against reinfection, cattle challenged with $\mathrm{Tir}^{+}$or $\mathrm{Tir}^{-}$strains at $\mathrm{C} 1$ were re-challenged 42 days later $(\mathrm{C} 2)$ with the $\mathrm{Nal}^{\mathrm{R}}$ parent strain (Figure 3). Cattle inoculated at $\mathrm{C} 1$ with WT had numerically lower mean shedding levels following $\mathrm{C} 2$, although their mean post-C2 shedding levels were nearly identical to the mean post-C2 shedding levels of cattle inoculated at $\mathrm{C} 1$ with the $\mathrm{Nal}^{\mathrm{R}}$ strain. Those inoculated at $\mathrm{C} 1$ with $\Delta$ tir (pEH86), $\Delta$ tir, or $\Delta$ tir (pACYC184) shed more following $\mathrm{C} 2$, although the results were not significant $(P=0.14)$. Cattle inoculated at $\mathrm{C} 1$ with the $\mathrm{Nal}^{\mathrm{R}}$ parent shed at approximately the same level following C2. However, the results also showed that although the magnitude and duration of shedding of WT post-C1 was significantly greater than that of the $\mathrm{Nal}^{\mathrm{R}}$ strain, the latter was able to infect cattle, and was shed at relatively high levels post-C2 in cattle that were exposed at $\mathrm{C} 1$ to non-flagellated $\operatorname{Tir}^{+}\left[\Delta\right.$ tir (pEH86)] or $\operatorname{Tir}^{-}(\Delta t i r)$ E. coli O157:H7 (Figure 3). Since initial infection with the tircomplemented mutant (pEH86) did not elicit any greater protection against $\mathrm{C} 2$ than did initial infection with the

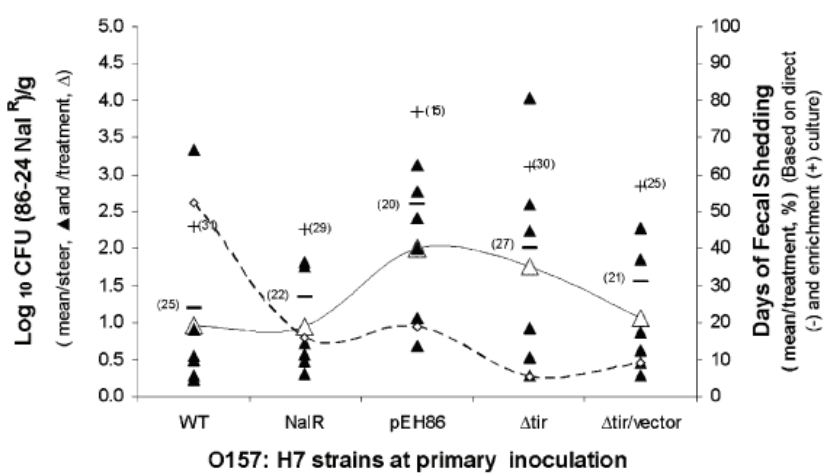

Figure 3. Magnitude (mean per steer, $\boldsymbol{\Delta}$; mean per treatment, $\Delta$; $\log _{10} \mathrm{CFU} / \mathrm{g}$ ) and duration of fecal shedding (mean per treatment; percentage of days), based on direct plating (DP) and enrichment (E-IMS) culture following oral challenge with the $\mathrm{Tir}^{+} 86-24 \mathrm{Nal}^{\mathrm{R}}$ strain (C2), 42 days after inoculation with one of five isogenic $\mathrm{Tir}^{+}$or $\operatorname{Tir}^{-}$E. coli O157:H7 strains, as shown on $X$ axis $(n=6)$. Data points for mean magnitude of fecal shedding after $\mathrm{C} 2$ are connected by a solid line (-). Fecal shedding was evaluated daily for 14 days. Mean magnitude of fecal shedding $\left(\diamond ; \log _{10} \mathrm{CFU} / \mathrm{g}\right)$ after primary inoculation $(\mathrm{C} 1)$, with data points for different treatment groups connected by a dashed line (- - ) is shown. Standard deviations for the duration of fecal shedding based on DP and E-IMS are shown in parentheses.

$\Delta t i r$ and $\Delta t i r$ vector control strains (Figure 3), no definitive role of enteric Tir exposure on protection was detected. It is possible that production of flagella by the inoculum strain played an important role in $\mathrm{C} 1$ infection.

\section{Discussion}

We hypothesized that inactivation of tir in E. coli O157:H7 would reduce its ability to colonize the intestine of adult yearling cattle and consequently be shed in the feces at a reduced magnitude and duration. Additionally, we hypothesized that initial infection with a $\operatorname{Tir}^{+}$ strain would reduce shedding following a second challenge in experimentally-inoculated cattle. The numerical means were consistent with the hypothesis that Tir expression enhances colonization, but the results were not statistically significant. Further, we were unable to determine whether Tir exposure at $\mathrm{C} 1$ had any effect on protection since the lack of flagellar expression by the $\Delta$ tir strains was a confounder in the study. Regardless, the results support the hypothesis that factors other than Tirintimin binding have an important function in colonization ([Dobbin et al., 2006] and [Naylor et al., 2005]).

The mechanisms regulating flagellar expression are complex and flagellum biosynthesis is usually co-regu- 
lated together with other virulence factors in Gram-negative bacteria (Soutourina and Bertin, 2003). Interestingly, a regulatory connection between the expression of flagella and other virulence factors (Soutourina and Bertin, 2003) including LEE (Sircili et al., 2004) has been identified in enteropathogenic $E$. coli. In the present study, with few exceptions, the non-flagellated strains did not colonize well. This could either point to a role for the flagellum itself in colonization, or a role for a factor that regulates both production of the flagella and some other property that actually impacts colonization.

Dobbin et al. (2006) reported that the class I flagellar regulatory gene, $\mathrm{fhC}$, and not the flagellin gene, $\mathrm{fliC}$ impacts E. coli $\mathrm{O} 157: \mathrm{H} 7$ colonization of calves. They noted that $f h D C$ is a global regulator of 29 operons not related to motility (Dobbin et al., 2006). These authors concluded that a functional flagellum is not necessary for colonization, and hypothesized that the reduced ability of their E. coli $\mathrm{O} 157 \triangle f h D C$ to colonize the terminal rectum of calves was due to effects on some factor other than flagella (Dobbin et al., 2006). In several bacterial species, flagellum-mediated motility enhances gastrointestinal colonization ([Richardson, 1991] and [Allen-Vercoe and Woodward, 1999]). The flagellum and not intimin has a significant function in persistent $E$. coli O157:H7 infection of chicks (Best et al., 2005).

The WT strain was shed at higher levels and for longer periods than the $\mathrm{Nal}^{\mathrm{R}}$ and tir-complemented mutant strains. However, in those animals given a $\mathrm{C} 1$ inoculum of non-flagellated E. coli $\mathrm{O} 157: \mathrm{H} 7$, the $\mathrm{Nal}^{\mathrm{R}}$ parent was shed at high levels $(P=0.14)$, comparable to that of the WT strain, following C2. This suggests that the host immunity to flagella might have contributed to the susceptibility of cattle to E. coli $\mathrm{O} 157: \mathrm{H} 7$ colonization after $\mathrm{C} 2$.

\section{Conclusion}

Variants of E. coli O157:H7 lacking flagellin expression, regardless of whether they expressed Tir, did not effectively colonize the intestines of inoculated cattle. Further, those given an initial inoculation with a nonflagellated variant of E. coli O157:H7 were more susceptible to a second challenge with motile E. coli $\mathrm{O} 157$ : $\mathrm{H} 7$ than those originally inoculated with motile strains. The cause of the loss of expression of flagellin was not addressed. These findings could either point to a function of the flagellum itself in colonization, or one for a factor that regulates both production of the flagella and some other effector that actually impacts colonization.

\section{Acknowledgements}

The project was supported by the National Research Initiative of the USDA Cooperative State Research, Education and Extension Service, grant \# 2001-02966, and USDA-CSREES Multi-State Research Project NC-1007.

\section{References}

Allen-Vercoe and Woodward, 1999 - E. Allen-Vercoe and M. J. Woodward, The role of flagella, but not fimbriae, in the adherence of Salmonella enterica serotype Enteritidis to chick gut explant, J. Med. Microbiol. 48 (1999), pp. 771-780.

Best ET AL., 2005 - A. Best, R. M. La Ragione, A. R. Sayers, and M. J. Woodward, Role for flagella but not intimin in the persistent infection of the gastrointestinal tissues of specific-pathogen-free chicks by shiga toxin-negative Escherichia coli O157:H7, Infect. Immunol. 73 (2005), pp. 1836-1846.

Cray and Moon, 1995 - W. C. Cray Jr. and H. W. Moon, Experimental infection of calves and adult cattle with Escherichia coli O157:H7, Appl. Environ. Microbiol. 61 (1995), pp. 1586-1590.

DeVinney et AL., 1999 - R. DeVinney, M. Stein, D. Reinscheid, A. Abe, S. Ruschkowski, and B. B. Finlay, Enterohemorrhagic Escherichia coli O157: $\mathrm{H} 7$ produces Tir, which is translocated to the host cell membrane but is not tyrosine phosphorylated, Infect. Immunol. 67 (1999), pp. 2389-2398.

DeVinney et al., 2001 - R. DeVinney, J. L. Puente, A. Gauthier, D. Goosney, and B. B. Finlay, Enterohaemorrhagic and enteropathogenic Escherichia coli use a different Tir-based mechanism for pedestal formation, Mol. Microbiol. 41 (2001), pp. 1445-1458.

DobBin ET AL., 2006 - H. S. Dobbin, C. J. Hovde, C. J. Williams, and S. A. Minnich, The Escherichia coli O157 flagellar regulatory gene $f h C$ and not the flagellin gene $f i C$ impacts colonization of cattle, Infect. Immunol. 74 (2006), pp. 2894-2905.

GrifFIN ET AL., 1988 - P. Griffin, S. Ostroff, R. Tauxe, K. Greene, J. Wells, J. Lewis, and P. Blake, Illnesses associated with Escherichia coli O157:H7 infections, Ann. Intern. Med. 109 (1988), pp. 705-712.

Girón ET AL., 2002 - J. A. Girón, A. G. Torres, E. Freer, and J. B. Kaper, The flagella of enteropathogenic Escherichia coli mediate adherence to epithelial cells, Mol. Microbiol. 44 (2002), pp. 361-379.

Hartland ET AL., 2000 - E. L. Hartland, S. J. Danielle, R. M. Delahay, B. C. Neves, T. Wallis, R. K. Shaw, C. Hale, S. Kneelton, and G. Frankel, The type III protein translocation system of enteropathogenic Escherichia coli involves EspA-EspB protein interactions, Mol. Microbiol. 35 (2000), pp. 1483-1492.

Khaitsa $E T$ AL., 2003 - M. L. Khaitsa, D. R. Smith, J. A. Stoner, A. 
M. Parkhurst, S. Hinkley, T. J. Klopfenstein, and R. A. Moxley, Incidence, duration, and prevalence of Escherichia coli O157: $\mathrm{H} 7$ fecal shedding by feedlot cattle during the finishing period, $J$. Food Prot. 66 (2003), pp. 1972-1977.

La Ragione $E T$ AL., 2005 - R. M. La Ragione, N. M. Ahmed, A. Best, D. Clifford, U. Weyer, W. A. Cooley, L. Johnson, G. R. Pearson, and M. J. Woodward, Colonization of 8-week-old conventionally reared goats by Escherichia coli O157:H7 after oral inoculation, J. Med. Microbiol. 54 (2005), pp. 485-492.

NAYLOR ET AL., 2007 - S. W. Naylor, A. Flockhart, P. Nart, D. G. E. Smith, J. Huntley, D. L. Gally, and J. C. Low, Shedding of Escherichia coli $\mathrm{O} 157: \mathrm{H} 7$ in calves is reduced by prior colonization with the homologous strain, Appl. Environ. Microbiol. 73 (2007), pp. 3765-3767.

NAYlor ET AL., 2003 - S. W. Naylor, C. Low, T. E. Besser, A. Mahajan, G. J. Gunn, M. C. Pearce, I. J. McKendrick, D. G. E. Smith, and D. L. Gally, Lymphoid follicle-dense mucosa at the terminal rectum is the principal site of colonization of enterohemorrhagic Escherichia coli O157:H7 in the bovine host, Infect. Immunol. 71 (2003), pp. 1505-1512.

NAYlor ET AL., 2005 - S. W. Naylor, A. J. Roe, P. Nart, K. Spears, D. G. E. Smith, J. C. Low, and D. L. Gally, Escherichia coli O157:
$\mathrm{H} 7$ forms attaching and effacing lesions at the terminal rectum of cattle and colonization requires the LEE4 operon, Microbiology 151 (2005), pp. 2773-2781.

RICHARDSON, 1991 - K. Richardson, Roles of motility and flagellar structure in pathogenicity of Vibrio cholerae: Analysis of motility mutants in three animal models, Infect. Immunol. 59 (1991), pp. 2727-2736.

SAS, 1999 - SAS, 1999. SAS/STAT ${ }^{\circledR}$ User's Guide (Release 8.00). SAS Inst. Inc., Cary, NC.

Sircili ET AL., 2004 - M. P. Sircili, M. Walters, L. R. Trabulsi, and V. Sperandio, Modulation of enteropathogenic Escherichia coli virulence by quorum sensing, Infect. Immunol. 72 (2004), pp. 2329-2337.

Smith Et AL., 2005 - D. R. Smith, R. A. Moxley, S. L. Clowser, J. D. Folmer, S. Hinkley, G. E. Erickson, and T. J. Klopfenstein, Use of rope-devices to describe and explain the feedlot ecology of Escherichia coli $\mathrm{O} 157: \mathrm{H} 7$ by time and place, Foodborne Pathog. Dis. 2 (2005), pp. 50-60.

Soutourina And Bertin, 2003 - O. A. Soutourina and P. N. Bertin, Regulation cascade of flagellar expression in Gram-negative bacteria, FEMS Microbiol. Rev. 27 (2003), pp. 505-523. 